\title{
LA MECÁNICA IMPRECISA DE LAS LOAS PALACIEGAS DE CALDERÓN ${ }^{1}$
}

\author{
Judith Farré \\ Consejo Superior de Investigaciones Científicas \\ Centro de Ciencias Humanas y Sociales \\ Instituto de Lengua, Literatura y Antropología \\ C/ Albasanz 26-28 \\ 28037 Madrid \\ Judith.farre@cchs.csic.es
}

[Anuario calderoniano (ISSN: 1888-8046), vol. extra, 1, 2013, pp. 147-161]

El teatro breve de Calderón, considerado en su conjunto, ha venido editándose en volúmenes donde no han sido recogidas sus loas. Así fue desde la edición de 1983 de Evangelina Rodríguez y Antonio Tordera y, más tarde, en la que llevara a cabo María Luisa Lobato en 1989. Al considerar el teatro breve de Calderón bajo la fórmula de

${ }^{1}$ Este trabajo se inscribe en el marco del programa Ramón y Cajal en la convocatoria 2008 ('Técnicas dramáticas de composición del teatro breve de los Siglos de Oro desde una perspectiva comparada', RYC-2008-02362) y del proyecto Edición y estudio del teatro breve de Antonio de Solís, financiado por la Subdirección General de Investigación, Desarrollo e Innovación del Ministerio de Economía y Competitividad (FFI-2011-25118). También cuenta con el patrocinio de TC-12, en el marco del Programa Consolider-Ingenio 2010, del Plan Nacional de Investigación Científica, Desarrollo e Innovación Tecnológica (SD2009-00033). 
'teatro cómico breve' o al poner de relieve su faceta como entremesista, se ha favorecido, sin duda, que las loas quedaran fuera del membrete por su tantas veces citada ausencia de graciosidad. Un claro ejemplo de ello son los juicios de valor que no pudo reprimir Emilio Cotarelo en sus anotaciones, después de transcribir muchas loas en apuntes manuscritos, así como las valoraciones que vertiera en su indispensable Colección de entremeses, loas, bailes, jácaras y mojigangas, donde pueden leerse comentarios como el que dedica a la loa de Bances Candamo para la fiesta teatral de Cómo se curan los celos y Orlando furioso (1691): "Lástima causa tanta fatiga de ingenio para cosa tan insulsa, y menos para aplicarla a aquella pobre momia viviente [Carlos II]. Algo ganaría la fiesta por el oído y la vista. Hay mucho canto en esta loa y se forma una danza de hachetas» ${ }^{2}$.

Con todo, en los últimos tiempos, una vez superada la visión historiográfica que consideraba los géneros breves como menores, las loas se han venido revalorizando como género teatral, ya sea por su valor documental para extraer noticias precisas sobre las circunstancias de representación de la pieza a la que precedía; ya sea por su valor intraespectacular y su función de establecer la inicial connivencia con el público, a partir de unos recursos bien definidos.

Ambas cuestiones, su valor informativo y las convenciones teatrales y metateatrales que sustentan la evolución de la loa como género dramático en la segunda mitad del siglo XVII, las apunta Evangelina Rodríguez, cuando estudia las referencias a la realidad espectacular del género:

La loa es la frontera, el telón que instaura el tiempo y el espacio de la convención escénica con respecto al tiempo y el espacio extra-escénicos, lo que con frecuencia se realiza ya de una manera convencionalizada. En este estadio la loa desarrolla una dimensión social interna, la vida cotidiana de la compañía teatral, las vicisitudes del actor y la pequeña glorificación de sus habilidades técnicas, histriónicas ${ }^{3}$.

En lo que atañe al proceso de edición, aunque las loas del corpus calderoniano no se hayan publicado aún como conjunto ni en los vo-

${ }^{2}$ Cotarelo, 2000, vol. I, p. XXXIX. Sobre la aplicación de esas fiestas al rey, que obedece a motivos más complejos de los que sugiere Cotarelo, ver Arellano, 1988a.

${ }^{3}$ Rodríguez Cuadros, 1998, p. 561. 
lúmenes de teatro breve de Calderón, ni hayan aparecido en muchas de las antologías de teatro breve publicadas hasta la fecha, sí se han editado recientemente algunas de ellas, bien en los volúmenes que dan cuenta de una fiesta teatral completa, bien en los recientes tomos de obras completas de Calderón a cargo de la Fundación Castro y coordinados por el grupo de Calderón de la Universidad de Santiago de Compostela. Caso aparte y "cuestión espinosa» es, en palabras de Ignacio Arellano, el de las loas sacramentales, pues no siempre es posible establecer con total seguridad ni la autoría ni la adscripción de una loa a su respectivo auto ${ }^{4}$.

A partir de los rasgos que configuran la tipología genérica de la loa palaciega ${ }^{5}$, y en lo que respecta a las escritas por Calderón, cabe decir que conservamos, con atribución segura, ocho loas para fiestas mitológicas ${ }^{6}$. De un repaso atento al corpus se desprende que se ajustan plenamente a la tipología genérica de la loa cortesana, si bien dos de ellas presentan algunos rasgos singulares. Se trata de la loa para Los tres mayores prodigios (1636) y de la que se integró en el festejo de El golfo de las sirenas (1657).

Creo que las diferencias de estas dos loas respecto al molde genérico deben tratarse desde la misma perspectiva general que se impone en el conjunto de la obra dramática de Calderón, ya que ratifican, como ocurre en otros géneros cultivados por el dramaturgo, su tendencia a la "combinación de rasgos de mecánica precisa e imprecisa (en el sentido de una presencia no constante) posibilitados por principios rectores dúctiles y generalistas» ${ }^{7}$. En los últimos tiempos, críticos como Jesús Sepúlveda (2003) o Juan Manuel Escudero (2011) ${ }^{8}$, bajo la premisa de un Calderón consciente de su oficio y de las me-

4 «Muchas loas que aparecen acompañando a los autos calderonianos, son de autoría incierta, falsa o pendiente de demostración; otras, sean o no auténticas, se atribuyen a autos distintos en testimonios diversos, sin que a menudo podamos asegurar a qué auto pertenecen; un mismo auto lleva loas diferentes en otros casos, etc... La dimensión relativamente breve de las loas y su fácil adaptación a circunstancias varias, provocan una movilidad notable, que dificulta el establecimiento de la autoría y del propio texto. Muy probablemente el mismo Calderón reutilizó algunas loas para asignarlas a autos distintos", Arellano, 1995, p. 46.

${ }^{5}$ Ver Farré 2002, 2009 y 2013.

${ }^{6}$ Ver también Lobato, 2000.

7 Escudero, 2011, p. 171.

8 pp. 163-182. 
cánicas imprecisas de los géneros teatrales, se han dedicado a revisar el haz y el envés de la comedia de capa y espada calderoniana, un subgénero dramático cuya taxonomía estaba plenamente fijada en el XVII ${ }^{9}$ y en el que, evitando reiteraciones y abusos miméticos, iban ensayándose nuevas e ingeniosas fórmulas combinatorias. El siguiente comentario de Sepúlveda a propósito de la evolución de la comedia de capa y espada:

Un canon de referencia evidente, un número limitado de posibilidades combinatorias, la necesidad de producir constantemente obras nuevas y las exigencias de un público experto constituyeron las murallas dentro de las que se vieron obligados a moverse innumerables dramaturgos ${ }^{10}$.

es equiparable, en todos los sentidos, al género dramático de la loa y, de manera muy específica, a las escritas por Calderón. Así pues, asumido el modelo de funcionamiento de la loa cortesana a mediados del siglo XVII, puede analizarse cómo Calderón ensaya nuevas fórmulas dramáticas para las loas palaciegas - concretamente en sus loas de 1636 y 1657 - , en las que plantea nuevas formas argumentales y escénicas para engastar todas las piezas de la fiesta, intentando superar las murallas del género y observándose una creciente dosis de comicidad, a partir de la intervención de los graciosos. Es cierto que el género de la loa palaciega no tiene la misma entidad dramática que otras formas breves, pero, si asumimos que la fiesta cortesana es un continuum dramático en el que todas las piezas desempeñan su función, la loa, aunque breve y casi en la periferia de la ficción dramática, ejerce su cometido. En este caso, además, de la mano de un Calderón que, como dramaturgo, se tomaba muy seriamente lo de resultar divertido a su público ${ }^{11}$.

La primera de las loas calderonianas, Los tres mayores prodigios, es la más extensa de todas y, además, la primera loa que conservamos de Calderón para la corte. Se representó la noche de san Juan de 1636 y en ella participaron tres compañías - la de Tomás Fernández, Pedro

${ }^{9}$ Son fundamentales los trabajos de Arellano, 1999, pp. 37-69 y posteriores.

10 Sepúlveda, 2003, p. 815. Para esas convenciones del género de capa y espada ver Arellano, 1988b.

11 Tomo como premisa inicial las conclusiones de Fernández Mosquera al analizar el planteamiento cómico de Calderón en Los tres mayores prodigios (2008, p. 176). 
de la Rosa y Antonio de Prado-, sobre otros tantos escenarios, concebidos como un decorado único. Esta loa resulta interesante porque plantea tres factores que serán decisivos en la evolución del género y que, a su vez, son indicativos del desarrollo del espectáculo teatral en la corte - esto es por la misma naturaleza circunstancial del género.

En primer lugar, cabe apuntar la búsqueda de nuevos planteamientos a la hora de integrar la loa al asunto de la comedia lo que, en definitiva, subraya la concepción de la fiesta como un todo. La loa se inicia con una invocación a la Noche por parte de Pales y Flora, quienes, a partir de los versos esticomíticos característicos en las aperturas del debate de méritos, reclaman su presencia para la conmemoración de la circunstancia festiva, es decir, la noche de San Juan. Tras esta confusión entre el asunto dramático y la circunstancia festiva, la aparición de la Noche por el escenario central, rodeada en los laterales por las dos ninfas, resulta paradigmática de la estructura y la nómina de personajes propias del género, puesto que las razones de su evocación tienen que ver con la previsión del festejo que va a llevarse a cabo y que, en realidad, ya se está poniendo en escena.

Las preguntas de Pales y Flora acerca de la comedia que va a representarse, molestas por el supuesto descuido de la Noche en los preparativos, propician la aparición en escena de los que serán los protagonistas de la comedia, Hércules, Jasón y Teseo. Un comentario de la Noche da pie a su salida al escenario: «Escuchad, que el argumento / os quiero poner presente / de toda la fiesta, a ver / lo qué la fiesta os parece, / que esto hizo la Antigüedad/ en sus fiestas muchas veces. / Escuchad, pues, su argumento / antes que se represente» ${ }^{12}$.

La novedad, en esta loa, reside en la ausencia de un debate de méritos propiamente dicho, que se sustituye por la puesta en escena de la síntesis argumental de la posterior comedia, aunque la loa se enmarca con las habituales invocaciones iniciales del género y termina con el ultílogo final, en el que se condensan las metáforas fosilizadas de elogio a los reyes. Así, Jasón y Teseo, para ayudar a Hércules - desesperado por el rapto de Deyanira a manos del centauro Neso-, se ofrecen a participar en su búsqueda. Después de que Hércules acuerde distribuir sus esfuerzos —él mismo se encargará de buscar en Áfri-

12 Todas las notas proceden de la edición de Fernández Mosquera en la Segunda parte de comedias (2007, p. 994). 
ca, mientras Teseo hará lo propio en Asia y Jasón recorrerá Europaaparece de nuevo la Noche, asistida por Pales y Flora, quienes escenifican el cierre alegórico característico del género, que anticipa la comedia que se representará a continuación.

Otro de los aspectos interesantes que anuncia esta loa es la relevancia de la puesta en escena y cómo se integra, no sólo en la comedia, sino también en la loa. Como ya estudió Teresa Chaves, aunque es una comedia mitológica de espectáculo, no contó con maquinaria para efectos y mutaciones - un aspecto que se señala en la $\operatorname{loa}^{13}$ - . El efectismo vino del teatro al aire libre que construyó Lotti, el lujoso vestuario, la gran cantidad de iluminación y las perspectivas de los decorados pintados por Lotti para cada escenario. Además, Quiñones de Benavente fue el responsable de los «intermedios de materia alegre» ${ }^{14}$.

La loa aprovecha las posibilidades de los tres escenarios. La acotación inicial precisa cómo las dos ninfas salen cada una por un escenario, mientras que el tablado central, reservado para la siguiente aparición de la Noche, queda de momento vacío: «Ha de haber tres teatros divididos el uno y los otros. En el de mano derecha sale Pales, ninfa. En el de mano izquierda Flora, ninfa, dejando desocupado el de en medio» (p. 991). Asimismo, la acotación para la primera salida a escena de la Noche precisa que sale desde lo alto: «En el tablado de en medio por lo alto de él sale la Noche» (p. 991). Un índice de la progresiva consideración que va adquiriendo la loa en el planteamiento global de la fiesta cortesana es, precisamente, la búsqueda de adecuación entre sus funciones dramáticas y sus propias soluciones escénicas. En esta ocasión se observa cómo la loa no se representa frente al telón de boca sino que se escenifica en los tres escenarios descubiertos e incorpora el pescante para el descenso de la Noche.

Además de las variaciones en el asunto dramático y de la importancia de la escenografia, otro aspecto de la loa que cabe apuntar se refiere a la comicidad y, en concreto, a los rasgos que adquiere en la loa Hércules. La comedia ha despertado diversas interpretaciones en-

13 «Flora: Poco importará, si tiene / algún teatro que haga / evidencia lo aparente. / Noche: Tampoco tiene apariencias. / PAles: Pues buena fiesta previenes. / Flora: Sin ingenio y sin adorno /¿no fuera mejor no hacerse?» (p. 994).

14 Chaves, 2004, pp. 60-63. 
tre la crítica, con variados matices, desde la trágica a la que analiza el final de la pieza sin una intención patética y entiende la comedia por su sentido festivo, al considerar el doble suicidio de Hércules y Deyanira desde la perspectiva trágico-grotesca de los graciosos que comentan la escena en un ambiente de música y baile ${ }^{15}$. Desde esta última perspectiva, y salvando las limitaciones que ofrece la loa por su brevedad, sí debe apuntarse la innovación que representa en la loa la presencia del angustiado y celoso Hércules, que, antes de iniciar la relación de su despecho, amenaza con lanzarse al vacío y darse sepultura (p. 995).

La situación, en el contexto de una loa palaciega, recuerda a los signos de desesperación que los autores solían mostrar en las loas de presentación de compañías, desconsolados y al borde del suicidio porque o bien sus actores se habían vuelto locos de tanto ensayar o bien, simplemente, los habían perdido o se habían quedado dormidos.

En esta ocasión, la primera réplica de Hércules en escena es «Dejadme dar la muerte» (p. 994) y, desde ese arrebato inicial, antes de que el valeroso héroe inicie su relación explicativa de lo acontecido, Teseo y Jasón intentarán calmar su «ira, rabia y furor», recordándole que «la desesperación no es valentía» para un héroe "valeroso» (p. 995). Este rabioso Hércules, tan sin seso, es un cambio en la nómina de personajes de las loas palaciegas que creo que tiene tanto que ver con la búsqueda de una unidad argumental y de sentido global para todo el festejo - es un preludio del final de la comedia-, como con la desesperación inicial que mostraban los autores en las loas de presentación de compañías y otros locos frecuentes en el teatro breve. Así, por ejemplo, era en la loa de Agustín de Salazar y Torres para La mejor flor de Sicilia, Santa Rosolea, en la que la escena inicial presentaba a Félix Pascual buscando ahorcarse o, con el mismo esquema, en la Loa con que empezó en Madrid la compañía del Pupilo, de Moreto.

Casi veinte años más tarde, las tendencias que planteaba Calderón en su primera loa cortesana van un paso más allá, con la loa que proyectó para el festejo de El golfo de las sirenas (1657). Si Los tres mayores prodigios conmemoraban la noche de san Juan de 1636, el Golfo de las sirenas de Calderón se representó el 17 de enero de 1657, a cargo de las compañías de Pedro de la Rosa y Diego Osorio. Hubo otra re-

\footnotetext{
15 Remito de nuevo al análisis de Fernández Mosquera, 2008, pp. 168-176.
} 
presentación el 12 de febrero del mismo año, durante los carnavales. Por lo pronto, tan solo cabe apuntar, de entrada, que se trata de circunstancias festivas parejas, pues san Juan y carnaval eran los momentos más álgidos para la fiesta en la corte de Felipe IV. También el hecho de que se repita la colaboración con una de las compañías más en boga en los escenarios de corte, la del autor Pedro de la Rosa, da cuenta del esmero con que se trazó el diseño de la fiesta, cuya escenografía fue de las últimas que llevó a cabo Baccio del Bianco, el escenógrafo encargado de sustituir a Lotti.

La incursión de Calderón en el modelo de la égloga piscatoria se quedó en una mera tentativa, como años antes ocurriera con otro experimento teatral, el llevado a cabo por Lope de Vega en La selva sin amor (1627), que también se refirió a ella como "égloga», y del que críticos como Maria Grazia Profeti han llegado a afirmar que «nos transmite un documento escalofriante de lo que hubiera podido ser la ópera española» ${ }^{16}$. La cuestión ya ha sido estudiada, tanto desde la perspectiva filológica como desde la óptica de la música. Desde la edición moderna de la fiesta completa que hiciera Sandra Nielsen (1989), la recepción crítica del festejo ha suscitado diversos estudios que se han ocupado de aspectos como la comicidad, el espacio, las reescrituras o la concepción de la fiesta como égloga y mojiganga. Mi interés ahora es el de considerar El golfo de las sirenas como fiesta palaciega desde la óptica del teatro breve y, fundamentalmente, desde las implicaciones que tuvo para la formulación genérica de la loa palaciega, lo que necesariamente conduce no sólo a valorar la función dramática de la loa en el conjunto de la fiesta, sino también en el de oficio de Calderón como dramaturgo.

Si en el anterior caso de Los tres mayores prodigios, tanto la parte de introducción como de desenlace y ultílogo eran protagonizadas por la Noche y las ninfas Pales y Flora, en esta ocasión los protagonistas de la loa para El golfo de las sirenas son todos personajes de la égloga: los pescadores Alfeo, Sileno y Lauro; las villanas Astrea y Celfa; las deidades Escila y Caribdis; el galán Ulises y sus criados Anteo y Dante, junto a cuatro sirenas, músicos pescadores y músicas villanas. Lo más llamativo de esta nómina de diez personajes de la loa es también la

16 Profeti, 1997, p. XX. 
inclusión del gracioso que es, además, el gracioso por excelencia, Cosme Pérez.

Un par de años antes, ya lo había puesto en práctica Antonio de Solís en otras loas como las de Un bobo hace ciento, Las amazonas o la loa para la comedia de Pico y Canente, escrita en colaboración por Luis de Ulloa y Rodrigo Dávila y representada en 1656 con ocasión del reestablecimiento de la salud de la Reina y que quizá coincidiera con la celebración de los carnavales. En esta última loa de Solís, Juan Rana acompañaba dormido a Apolo en una nube, a sus pies, mientras descendía desde lo alto. Tras despertarse, brindaba con vino por la salud de la Reina y participaba en el elogio final a las damas del público, glosando la metáfora que elogiaba a las damas como flores.

La impresión es que la presencia del gracioso en estas loas de Solís es más bien una concesión al gusto de la familia real que una incorporación meditadamente integrada a la dramaturgia de toda la fiesta. Así se desprende, por ejemplo, al valorar la trabazón argumental entre todas las piezas dramáticas que componen el festejo. Esa impresión se confirma al leer la correspondencia de Baccio del Bianco en la que, al hablar de esa representación, se cuestionaba la pertinencia de esa mescolanza entre el 'gracioso de la reina' y el dios Apolo ${ }^{17}$.

Volviendo a Calderón, la loa de El golfo de las sirenas, a diferencia de la loa de Los tres mayores prodigios, no pone en escena una síntesis del argumento de la comedia que seguirá a continuación, sino que la coordinación que ensaya va más allá del enlace argumental y favorece que la loa, ya con un asunto dramático definido en términos de acción, que se retoma en la posterior égloga, se integre de pleno en la dramaturgia de toda la fiesta. Esta integración cabal a todo el festejo significa, además, que la loa comparta, como aderezo teatral de la pieza extensa, cartel con la mojiganga, un género dramático que, por naturaleza, supone un avance más en la comicidad respecto al entremés tradicional.

Este aumento de la graciosidad en la loa de 1657 se observa a partir de varias estrategias dramáticas. En un primer grupo cabe considerar los principales engarces entre las tres piezas del festejo ${ }^{18}$, que tie-

17 Bacci, 1963, p. 75.

18 En el nivel de la puesta en escena, otros enlaces son la repetición del canto «úpiter, piedad, / Neptuno, clemencia»y duplicidades como el terremoto. 
nen que ver con el gracioso Alfeo. En el nivel argumental, el miedo de Alfeo en la loa a participar en la celebración de las deidades extranjeras, para no contrariar a Escila y Caribdis y desatar su ira, se confirma en la égloga donde, por una serie de casualidades, siempre que las dos diosas intenten perseguir a Ulises, acabarán topándose con Alfeo y con Celfa. La villana quedará presa en una torre y Alfeo, siempre miedoso, en su intento por rehuir a unas y a otro, termina en el mismo barco que Ulises, que ha sido embestido por terremotos y sirenas. Los tripulantes de la embarcación consiguen avanzar con el viento favorable y protegiendo la vista y el oído, pero el gracioso es lanzado al mar por Dante y por Alfeo, para aligerar peso en la embarcación y tras negarse este a remar. En el mar, un pez se come a Alfeo. La égloga termina con el sepulcro de plata de las vencidas Escila y Caribdis y la pesca de Sileno, que ha resultado ser el pescado que se comió al gracioso. Con la aparición de Alfeo vestido de salvaje desde la boca del «marino monstruo», «empieza la mojiganga».

Sin más transición, la mojiganga empieza con las ya tópicas dudas de Juan Rana acerca de dónde se encuentra, que en este caso están plenamente justificadas, ya que ha sido engullido por un pez y devuelto después a la orilla. Como antes Ulises en la égloga, Alfeo quiere saber dónde se encuentra y las explicaciones permiten retomar el motivo inicial, la celebración de las nuevas deidades en la 'Zarzuela de Trinacia'. Varias alusiones a la tramoya y a la máscara de Juan Rana favorecen los distintos equívocos de la mojiganga, que terminará con una caída de Alfeo, ya convertido en Juan Rana, que se anuncia como el cierre de la mojiganga: «Juan Rana se ha hecho pedazos» (v. 1929).

Otro elemento que tiene que ver con la comicidad es la confusión entre el espacio real y el simbólico de la representación, ya estudiado por María Luisa Tobar (2005), que, además, puede relacionarse con la parodia de ciertos motivos característicos de la tipología de la loa palaciega y que el propio Calderón, como otros tantos dramaturgos áulicos, ensayó en sus loas palaciegas. Como muestra, la invocación inicial a la Aurora. Es éste uno de los tópicos del género, pues la llegada de un nuevo día adquiere en las loas una dimensión simbólica que, desde la tradición del amanecer mitológico, concuerda con la ambientación en escena del lugar ameno. Remite, además, a una de las metáforas fundamentales para el elogio de la reinas. Esta llamada 
inicial al alba es habitual que se realice a través del canto de personajes alegóricos o mitológicos. Bien, desde esta convención, los primeros 80 versos de la loa del Golfo presentan a Alfeo, pescador rústico, que dialoga con la villana Celfa, a quien comunica su enojo con «todos cuantos poetas» (v. 24) que describen un paisaje idealizado que nada tiene que ver con su frío entorno natural en el que el alba está cubierta «de tupidas nieblas» $\mathrm{y}$

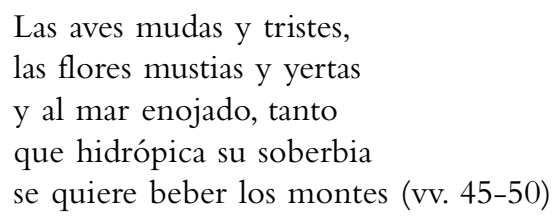

A la réplica de Alfeo le sigue Celfa, que invoca a los cuatro Elementos -otro recurso característico en los procesos de debate de méritos de las loas palaciegas - que, desde dentro, responderán cantando para ratificar el efecto devastador del invierno en la naturaleza. La recolección final, a coro, de todos los argumentos diseminados confirma

Que porque el Enero con ellos embiste, las flores se pasman, los rayos tiritan, las ondas se quejan, los pájaros gimen (vv. 78-80)

A partir de este cuadro inicial se desplegarán las líneas argumentales del festejo: la llegada de las nuevas deidades-la llamada festiva de los rústicos para celebrarlas-el miedo a participar de Alfeo, por no contrariar a Escila y Caribdis-la aparición de Ulises y su huida ante la persecución de las deidades mitológicas-la victoria de Ulises-la celebración en la Zarzuela de Trinacia.

En las loas palaciegas lo esencial consistía en recrear un espacio simbólico ambientado en una naturaleza armónica e idealizada, en el que participaban deidades mitológicas y alegóricas, así como los cuatro elementos como sus principios constitutivos más esenciales. En dicha ambientación se escenificaba un debate de méritos por conseguir el patrocinio festivo en la celebración y, tras el consenso final en el que se sumaban todas las propuestas conmemorativas enfrentadas, el reconocimiento del espacio y tiempo reales implicaba la solución festiva. 
En esta ocasión, se revuelven el espacio real y simbólico en un constante ir y venir, que Alfeo, primero como pescador rústico y después como Juan Rana, es incapaz de manejar. Los desajustes que provocan sus intervenciones generan un efecto cómico constante, lo que dota de unidad a la fiesta. El equívoco que genera que el pescador haya sido engullido por un pez y finalmente rescatado al ser pescado, resume bien la comicidad manifiesta de las tres piezas teatrales. Esta ridícula confusión de espacios y de niveles de la representación generan en la loa un proceso inverso al característico del género, donde el registro simbólico es un correlato objetivo para el elogio de la circunstancia.

Ciertamente, ya no habrá más incursiones en el modelo de la égloga piscatoria, aunque esta manifiesta comicidad de la loa que se convierte en trabazón argumental de todo el festejo sí será un motivo que, a partir de Calderón, ensayarán otros dramaturgos de corte en sus loas palaciegas. El ejemplo más inmediato es el de Antonio de Solís en Triunfos de Amor y Fortuna (1658), una fiesta cuyo éxito le valió el ascenso como cronista de Indias y propició que el marqués de Liche fuera nombrado alcalde del Buen Retiro en septiembre del mismo año.

Otros casos que reproducen modelos dramáticos similares son el de la Loa por los papeles de palacio, de Francisco de Avellaneda (quizá de 1659); la Loa curiosa del mismo Avellaneda para La flor del Sol (1675); una reescritura de El golfo de las sirenas, llevada a cabo por Baltasar de Funes Villalpando, representada en la corte en 1684 y que, entre las variantes que presenta, los versos que aprovechan uno de los momentos cumbre de comicidad, como es la aparición del gracioso por la boca del marino monstruo. En esta ocasión, se saca partido a que Escamilla ejerce de gracioso, en lugar de Cosme Pérez, para generar un chiste

Celsa

[...] mas es ver un pez monstruoso que entre una y otra basca

a la arena de esta orilla vomita otro sin escama.

AlfEO

(Dentro.) Pero no sin Escamilla ${ }^{19}$.

19 Según Urzáiz, 2002, p. 377. 
Así pues, para concluir, creo que las loas cortesanas, como ocurre también con las fiestas mitológicas en las que se inscriben y las comedias a las que preceden, también dan pie a esa mecánica imprecisa que tantas veces ensayó Calderón en la que se observa un creciente aumento de la comicidad, esas tonalidades entremesiles que estudió Trambaioli. Ciertas circunstancias festivas como el carnaval y san Juan predisponen a ello, pero, además, el teatro palaciego en esos años de 1657 a 1660, un período marcado por la necesidad de solemnizar la llegada de los dos hijos infantes de Felipe IV ${ }^{20}$ también experimentó un progresivo aumento de la graciosidad. Del mismo modo, las loas de palacio se hicieron eco de ello, como la comedia y el entremés. Si bien nunca llegó a olvidarse el ultílogo final en el que se condensaban las alabanzas de cierre características del género, sí puede constatarse cómo, siguiendo la estela de Calderón, muchas loas incorporaron un conflicto dramático a su acción protagonizado por graciosos, al igual que otras tantas siguieron el esquema del género y su espectacular puesta en escena en clave alegórica.

${ }^{20}$ Cotarelo, 1916, p. 92. 


\section{Bibliografía}

Arellano, I., «Bances Candamo poeta áulico. Teoría y práctica en el teatro cortesano del postrer Siglo de Oro», Iberoromania, 27-28, 1988a, pp. 4260.

- "Convenciones y rasgos genéricos en la comedia de capa y espada», Cuadernos de teatro clásico, 1, 1988, pp. 27-49.

- Convención y recepción. Estudios sobre el teatro del Siglo de Oro, Madrid, Gredos, 1999.

- y Á. Cilveti (eds.), El año santo en Roma, Pamplona / Kassel, Universidad de Navarra / Reichenberger, 1995.

Bacci, M., «Lettere inedite di Baccio del Bianco», Paragone, 14, 1963, pp. 6877.

Calderón de la Barca, P., Entremeses, jácaras y mojigangas, ed. E. Rodríguez y A. Tordera, Madrid, Castalia, 1983.

- Teatro cómico breve, ed. M. ${ }^{a}$ L. Lobato, Kassel, Reichenberger, 1989.

- El golfo de las sirenas, ed. S. L. Nielsen, Kassel, Reichenberger, 1989.

- Loa a los tres mayores prodigios en Comedias, II. Segunda parte de comedias, ed. S. Fernández Mosquera, Madrid, Biblioteca Castro, 2007, pp. 990-1005.

Cienfuegos Antelo, G., El teatro breve de Avellaneda. Estudio y edición, Madrid, Fundación Universitaria Española, 2006.

Cotarelo, E., Sebastián de Prado y su mujer Bernarda Ramírez, actores famosos del siglo XVII, Madrid, Tip. de la Revista de Archivos, Bibliotecas y Museos, 1916.

- Colección de entremeses, loas, bailes, jácaras y mojigangas, Madrid, Bailli-Baillière. Ed. facsímil con estudio preliminar e índices por J. L. Suárez y A. Madroñal, Granada, Universidad de Granada, 2000.

Chaves, M. ${ }^{\text {a }}$ T., El espectáculo teatral en la corte de Felipe IV, Madrid, Ayuntamiento de Madrid, 2004.

Escudero, J. M., "El escondido y la tapada: La mecánica imprecisa de la comedia de capa y espada en Calderón», en Calderón: del manuscrito a la escena, ed. F. A. de Armas y L. García Lorenzo, Madrid / Frankfurt, Iberoamericana / Vervuert, 2011, pp. 163-188.

Farré Vidal, J., Dramaturgia y espectáculo del elogio. Loas completas de Agustín de Salazar y Torres, Kassel, Reichenberger, 2002.

— «Aproximaciones al itinerario de un género teatral en el siglo XVII, a propósito de las loas palaciegas de Calderón de la Barca», Anuario calderoniano, 2, 2009, pp. 143-180.

— «logio, mecenazgo y profesionalización del teatro español de la segunda mitad del siglo XVII: la loa en la órbita entremesil», Bulletin of Spanish Studies, 90, 2, 2013, pp. 157-175. 
Fernández Mosquera, S., «Las comedias mitológicas de Calderón: entre la fiesta y la tragedia. El caso de Los tres mayores prodigios», en Hacia la tragedia áurea. Lecturas para un nuevo milenio, ed. F. A. de Armas, L. García Lorenzo y E. García Santo-Tomás, Madrid / Frankfurt, Iberoamericana / Vervuert, 2008, pp. 153-180.

Ferrer Valls, T., "El golfo de las sirenas de Calderón: égloga y mojiganga», en Giornate Calderoniane, Calderón 2000. Atti del Convegno Internazionale Palermo 14-17 Dicembre 2000, ed. E. Cancelliere, Palermo, Flaccovio Editore, 2003, pp. 293-308.

Lobato, M. ${ }^{a}$ L., "Calderón, cisne del Manzanares. Loas cortesanas y conciencia artística», Bulletin of Hispanic Studies, 77, 2000, pp. 357-389.

Profeti, M. ${ }^{a}$ G., "El último Lope», en La década de oro de la comedia española (1630-1640), ed. F. Pedraza y R. González Cañal, Almagro, Universidad de Castilla-La Mancha / Festival de Almagro, 1997, pp. 11-39.

Rodríguez Cuadros, E., La técnica del actor español en el Barroco. Hipótesis $y$ documentos, Madrid, Castalia, 1998.

Sepúlveda, J., «Haz y envés de convenciones en El escondido y la tapada de Pedro Calderón de la Barca», Criticón, 87-88-89, 2003, pp. 815-826.

TobAr, M. ${ }^{a}$ L., "El golfo de las sirenas: el espacio real y el espacio simbólico", en El siglo de oro en el nuevo milenio, ed. C. Mata y M. Zugasti, Pamplona, Eunsa, 2005, vol. 2, pp. 1627-1644.

Trambaioli, M., «Tonalidades entremesiles en el teatro palaciego de Calderón", en Atti del $1^{\circ}$ Seminario Internazionale sui Secoli d'oro (Firenze, 8-12 settembre 1997), Firenze, Alinea Editrice, 1998, pp. 287-303.

Urzáiz Tortajada, H., "Más sobre escritura teatral: El golfo de las sirenas, de Calderón ¿y Funes?», en Calderón 2000: Homenaje a Kurt Reichenberger en su 80 cumpleaños, ed. K. Reichenberger e I. Arellano, Kassel, Reichenberger, 2002, vol. 1, pp. 369-382.

- «El desvergonzado en palacio: los graciosos en las comedias mitológicas», Acotaciones. Revista de Investigación Teatral, 17, 2006, pp. 9-43. 